\title{
Brand Positioning of the Sport Sciences Research Institution of Iran using Perceptual Mapping Technique
}

\author{
${ }^{1}$ Seyed Mehdy Rasooli, ${ }^{2}$ Mahmood Fazel Bkhsheshi, ${ }^{1}$ Hossein Zareian ${ }^{*}$ \\ ${ }^{1}$ Department of Sport Management, Sport Sciences Research Institute, Tehran, Iran. ${ }^{2}$ University of Sistan and Bluchestan, \\ Zahedan, Iran.
}

\begin{abstract}
Background. Brands are the most important source of emotional attachment with the consumer, it should be used as a vital tool for attracting and retaining customers of the organization and various sports organizations, should follow the theoretical principles related to brand management and brand loyalty and move towards strategic brand management as a superior marketing philosophy. Objectives. The purpose of this research was to position the Sport Sciences Research Institution of Iran using the Perceptual Mapping Technique. Methods. Competitive characteristics and strategic rivals of the Sport Sciences Research Institution were obtained from Rasooli Research (2013). Competitive characteristics and competitors were then prioritized using a researcher-made questionnaire and hierarchical method. The statistical population of this research consisted of the academic staff of the country including faculty members and graduate students. Analytic hierarchy analysis was used to prioritize the research variables. Results. Based on the obtained results, perceptual maps of the brand position of the research Center were depicted. The results showed that the position of brand of Sport Sciences Research Institution among academic researchers of the country in terms of research services, facilities and products was higher than other competitors while the field of educational services after physical education faculties was in the second place; and effort should be made in this area to promote their brand. Conclusion. In the competitive and turbulent environment of today, the role of brand as consumers' decision-making guide is becoming more important. Branding should therefore be considered as a continuous activity in all modes.
\end{abstract}

KEY WORDS: Branding, Brand Awareness, Brand Association, Perceptual Maps, Sport Sciences Research Institution.

\section{INTRODUCTION}

Distinction is a prerequisite for sustainability in competitive markets, and positioning is a process for creating a distinction. Positioning at the brand level means that each brand must own and hold a word in the minds of customers (1). This word, which is a factor in communicating with customers in competitive markets, emphasizes the product's characteristics, which, because of its ability to supply that characteristic to competitors, wants to be known in the minds of customers through that term to implicitly induce a reason for being selected by the customer (2).

Darling (2007) (3) defined positioning as a clear, superior, and desirable manifestation of a product in the minds of customers in the intended market, according to the products of rival companies. According to Chen and Uysal (2008) (4), positioning is the way each product should be

*. Corresponding Author:

Hossein Zareian

E-mail: h.zareian@ssrc.ac.ir 
introduced from the beginning, and perhaps the most important reason is the fact that, today, customers are exposed to a storm of information and advertising. Rasooli (2013) (5) opined that the strategy of positioning is to search the world of products from the point of view of customers, and then obtain a desirable and vacant space in their minds. In order to realize the strategy of positioning, first, the combination of proper characteristics in his view should be known, and then plans should be made to meet them (6).

Drawing perceptual maps is among the conventional ways of determining the position of the brand. Benedict et al. (1999) (7) argued that perceptual maps have been used as a strategic management tool since 1970. Ries and Trout (2001) (8) argued that this map has a unique ability to simplify the complex relationships between market competitors and customer decision-making criteria. Perceptual map is a process that reflects the perceptions of respondents. This map reflects the perceptions of respondents from the company, products, services, competitors, etc., and is usually displayed in a two-dimensional form.

Nowadays, the sports industry has grown and become widespread, and there are numerous organizational brands in the industry (9). A glimpse into the developed countries in the field of sports suggests their accurate investment and planning in the field of education and research in this field. Countries such as Australia, the United States, England, Canada, and New Zealand have greatly contributed to the development and growth of a variety of public and athletic sports by formulating strategic plans in the field of sports sciences (10), such that the main goal of creating the universities of the aforementioned countries, while educating the workforce, was to provide the ground for joint cooperation between the industry and the university, promote the level of science and provide the ground for the development of economics and industry at the local and regional level as a special mission of these universities. The emphasis on the training of the workforce required by the industries gradually led to the formation of higher education institutions under the name of "Polytechnics" and made the relationship between university and industry more meaningful (5). In this regard, following the need for research for the development of sports in the country, the Council for the Development of Higher Education established the first and the largest scientific research center of Iranian sports called the "Center for Physical Education and Sports Science". In 2011, the center was promoted to the Research Center for Physical Education and Sports Science. In order to identify the status of this research Center as a major sports scientific reference, in all sectors of the society as well as internationally, like other service organizations, the need for a marketing and strategic brand management program is felt (10). In order to achieve the brand position of the Sport Sciences Research Institution, it is necessary to identify the competitive characteristics and competitors available on the market.

Rasooli (2013) (5) identified both factors in his research. The research showed that the Sport Sciences Research Institution competes in four areas viz, education, research, products and facilities with its competitors, including physical education faculties, the Ministry of Sports, private institutions and the National Olympic Academy. Several studies have also been conducted to identify the factors affecting organizational image and the position of scientific and educational organizations. Gotsi and Wilson (1999) (11) also argued that the target audiences of universities examine the mental image of the institution from a number of aspects, including: academic reputation, physical appearance of the campus, cost, individual attention, determining of the occupational level, location, distance from home, preparation programs for graduation and entry into the labor market. Kalafatis et al. (2001) (12) concluded that controllable factors of mental image (organizational factors) by the university (existence of strong science programs, sports programs, libraries and technical facilities) are stronger indicators for evaluating the image of the brand compared to the environmental factors (for example, location, comparison of costs compared to other universities and the degree of having educational standards than other universities). Price et al. (2003) (13) stated that the quality of facilities plays an effective role in choosing an educational institution by students. Ivy (2008) (14) showed that seven distinct factors, apart from four marketing factors, are effective in selecting university brands, namely: program (trends), 
people (faculty members, staff and other students), promotion (public relations and website), prominence, price (tuition) and benefits. In a study by Dourate et al. in (2010) (15), which is in correlation with the research of Arpan et al. (2003) (16), Palacio et al. (2002) (17) considered the mental image of the university as a multidimensional construct affecting four factors namely: job opportunities, communication, social university life and the subjective image of fields. The dimensions affecting the university brand in the perspective of Martinez (2009) (18) and Cowart et al. (2010) (19) include: community service provision, faculty member activities, executive management, as well as technical and physical infrastructure. Their findings showed that factors such as the presence of the university in the cyberspace (Internet), as it is culturally presented improves executive management processes, such as creating e-mail monitoring and seeking work for graduates. Gorchlez (2009) (20) concluded that factors such as public relations, marketing, developmental projects, management, and affairs of university graduates are effective in building a strong domestic brand.

Bagheri et al. (2010) (21) and Megan et al. (2011) (5) emphasized the use of universities' transparent and desirable marketing and appropriate communication and university identity and culture for brand promotion. Hosseini et al. (2012) (22) identified university brand assessment characteristics as: providing students with the opportunity to study while working, ease of entry into the university to study, the possibility of studying at work, the provision of a range of extracurricular activities (sports, entertainment, science, etc.), providing students with the necessary facilities (computer equipment, library, laboratory, etc.), having an appropriate educational planning system, the manner of treating and respecting students, the value of the received certificate in the labor market, the proportion of tuition and the university moves toward progress. Finally, Rasooli et al. (2012) (9), Dastom et al. (2013) (23) and Sa'atchian et al. (2015) (24) highlighted the efforts in line with increasing the relationship between the academic sector and the sports industry in order to improve brand position in both sectors. Careaga (2017) (25), confirmed the role of strategy, market research and internal engagement in building a university brand.
Rauschnabel, et al (2016) (26) mentioned brand personality management as a key element to improve university brand and Rutter, et al (2017) (27), founded that while the brand personality trait of sincerity was common for all of the Higher Education Institutions, there was clear differentiation on the basis of other traits, demonstrating that brand personality deepens understanding of HEI positioning.

Considering the affective factors mentioned in the brand image and determining the position of scientific organizations and since brands are the most important source of emotional attachment with the consumer, it should be used as a vital tool for attracting and retaining customers of the organization. In this regard, managers of the Center of Physical Education and Sport Sciences, in order to promote the status of this scientific center in the community and to identify their goals and abilities to solve problems of the society and various sports organizations, should follow the theoretical principles related to brand management and brand loyalty and move towards strategic brand management as a superior marketing philosophy. Thus, the purpose of this research was to identify the current position of the brand of the Center of Physical Education and Sport Sciences of Iran.

\section{MATERIALS AND METHODS}

The present research is a descriptive-analytical research that was conducted using a mixed quantitative method

Participants. The statistical population of this study included graduate students and faculty members in physical education as an educational and research market sample. The statistical sample included 30 faculty members and postgraduate students in physical education who were members of the working groups and groups of this organization, and who knew about the research Center and its tasks and functions; and were purposefully considered.

Instrument. A researcher-made questionnaire was used to prioritize the competitive dimensions of the research Center and its competitors' positions were utilized based on a hierarchical analysis technique.

In order to draw perceptual maps, it was necessary to determine the rivals and competitive characteristics of the research Center, which were 
obtained from the results of Rasooli's research (2013) (5), regarding the brand of the Sport Sciences Research Institution.

Statistical Analysis. In order to prioritize the competitive characteristics and rivals of the research Center, Analytical Hierarchy Analysis was used with the Excel software. Finally, the values obtained from pseudohierarchical analysis were used in perceptual map tables to identify the status of each organization with respect to the characteristics studied in relation to the Physical Education Research Center.

\section{RESULTS}

In this section, first, the priority of the Center's competitive characteristics among the strategic competitors of the organization was discussed and then, based on the perceptual maps, the research position of the research Center was determined among its competitors (Table 1).

Based on the findings of the analysis of the variables of facilities of physical education and sport sciences, the weighted mean weight of the variables of the facilities of physical education institutions and sports sciences were prioritized. Accordingly, the Center for Physical Education and Sport Sciences with a mean weight of $\mathrm{M}=0.35$ had the highest priority in terms of facilities of physical education institutions and sports science from the point of view of physical education specialists. This calculation was carried out in a 5 $\times 5$ matrix corresponding to the five variables in the facilities of physical education and sport sciences, with an incompatibility of 0.02 (Table 1).

Table 1. Comparison of the paired results and prioritization of facilities for physical education and sport sciences

\begin{tabular}{clc}
\hline No. & \multicolumn{1}{c}{ Variables of facilities } & The mean of weighted weights \\
\hline $\mathbf{1}$ & The facilities of the Faculty of Physical Education and Sport Sciences & 0.35 \\
\hline $\mathbf{2}$ & The facilities of the Olympic Academy & 0.23 \\
\hline $\mathbf{3}$ & The facilities Faculties of Physical Education & 0.23 \\
\hline $\mathbf{4}$ & The facilities at the Ministry of Sports Studies Center & 0.12 \\
\hline $\mathbf{5}$ & The facilities of private institutions & 0.06 \\
\hline
\end{tabular}

Table 2. The results of pairwise comparison and prioritizing variables of educational services of physical education and sports science Centers

\begin{tabular}{clc}
\hline No. & \multicolumn{1}{c}{ Variables of educational services of sports sciences Centers } & The mean of weighted weights \\
\hline $\mathbf{1}$ & The educational services of the Faculty of Physical Education & 0.34 \\
\hline $\mathbf{2}$ & The educational services of the research center of Physical Education & 0.32 \\
$\mathbf{3}$ & The educational services of the Olympic Academy & 0.16 \\
\hline $\mathbf{4}$ & The educational services at the Ministry of Sports Studies Center & 0.11 \\
$\mathbf{5}$ & The educational services of private institutions & 0.05
\end{tabular}

Based on the findings of the analysis of the variables of educational services of physical education and sport sciences, the weighted mean weight of the variables of the educational services of physical education institutions and sports sciences were prioritized. Accordingly, the Center for Physical Education and Sport Sciences with a mean weight of $M=0.341$ had the highest priority in terms of educational services of physical education institutions and sports science. This calculation was carried out in a $5 \times 5$ matrix corresponding to the five variables in the facilities of physical education and sport sciences, with an incompatibility of 0.02 .
Based on the findings of the analysis of the variables of research services of physical education and sport sciences, the weighted mean weight of the variables of the research services of physical education institutions and sports sciences were prioritized. Accordingly, the Center for Physical Education and Sport Sciences with a mean weight of $\mathrm{M}=0.461$ had the highest priority in terms of research services of physical education institutions and sports science. This calculation was carried out in a $5 \times 5$ matrix corresponding to the five variables in the services of physical education and sport sciences, with an incompatibility of 0.04 . 
Table 3. The results of pairwise comparison and prioritizing variables of research services of physical education and sports science Centers

\begin{tabular}{ccc}
\hline No. & Variables of educational services of sports sciences Centers & The mean of weighted weights \\
\hline $\mathbf{1}$ & The research services of the research center of Physical Education & 0.46 \\
\hline $\mathbf{2}$ & The research services of the Faculties of Physical Education & 0.23 \\
\hline $\mathbf{3}$ & The research services of the Olympic Academy & 0.14 \\
\hline $\mathbf{4}$ & The research services at the Ministry of Sports Studies Center & 0.10 \\
\hline $\mathbf{5}$ & The research services of private institutions & 0.05 \\
\hline
\end{tabular}

Table 4. The results of pairwise comparison and prioritizing variables of products of physical education and sports science Centers

\begin{tabular}{rlc}
\hline No. & \multicolumn{1}{c}{ Variables of products of sports sciences Centers } & The mean of weighted weights \\
\hline $\mathbf{1}$ & The products of the research center of Physical Education & 0.42 \\
\hline $\mathbf{2}$ & The products of the Faculties of Physical Education & 0.20 \\
\hline $\mathbf{3}$ & The products of the Olympic Academy & 0.15 \\
\hline $\mathbf{4}$ & The products at the Ministry of Sports Studies Center & 0.12 \\
\hline $\mathbf{5}$ & The products of private institutions & 0.08 \\
\hline
\end{tabular}

Based on the findings of the analysis of the variables of products of physical education and sport sciences, the weighted mean weight of the variables of the products of physical education institutions and sports sciences were prioritized. Accordingly, the Center for Physical Education and Sport Sciences with a mean weight of $\mathrm{M}=$ 0.421 had the highest priority in terms of products of physical education institutions and sports science. This calculation was carried out in a $5 \times 5$ matrix corresponding to the five variables in the services of physical education and sport sciences, with an incompatibility of 0.02 .

In the first perceptual map (Figure 1), the position of the research Center and its strategic competitors in two areas of educational services and facilities are illustrated. As shown in Figure 1, the Physical Education Research Center has a much better position than other competitors in the field of facilities and educational services, and in this area, only physical education faculties are close to the research Center. In the following, areas of facilities and research services were considered.

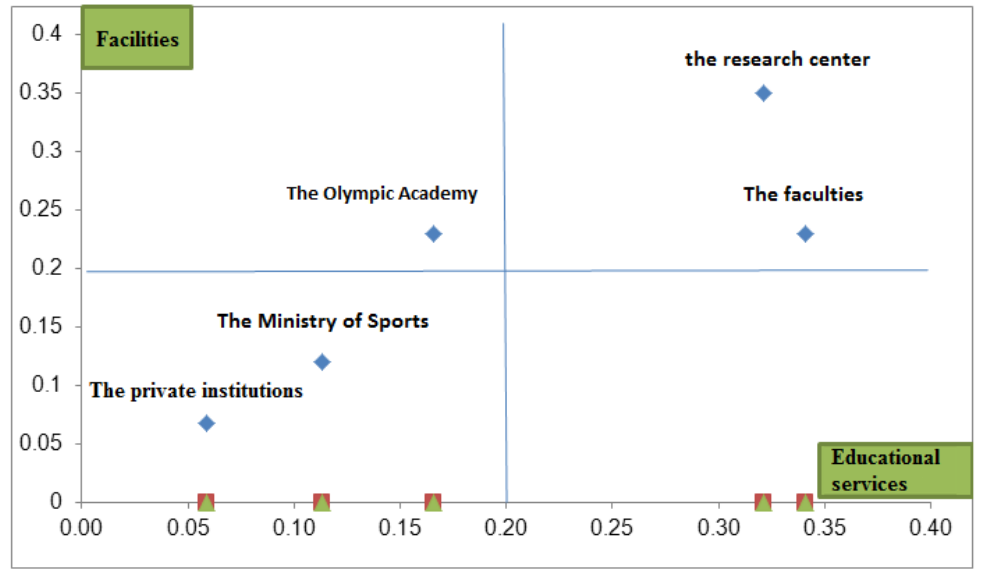

Figure 1. Perceptual map based on variables of facilities and educational services.

As shown in Figure 2, the Physical Education Research Center has a much better position than other competitors in the field of research facilities and services, and in this area only the physical 
education faculties are close to the research Center.

As shown in Figure 3, the Physical Education Research Center has a much better position than other competitors in the field of facilities and products. In this area, only physical education faculties are close to the research Center. In this regard, the National Olympic Academy has a better position than the previous ones.

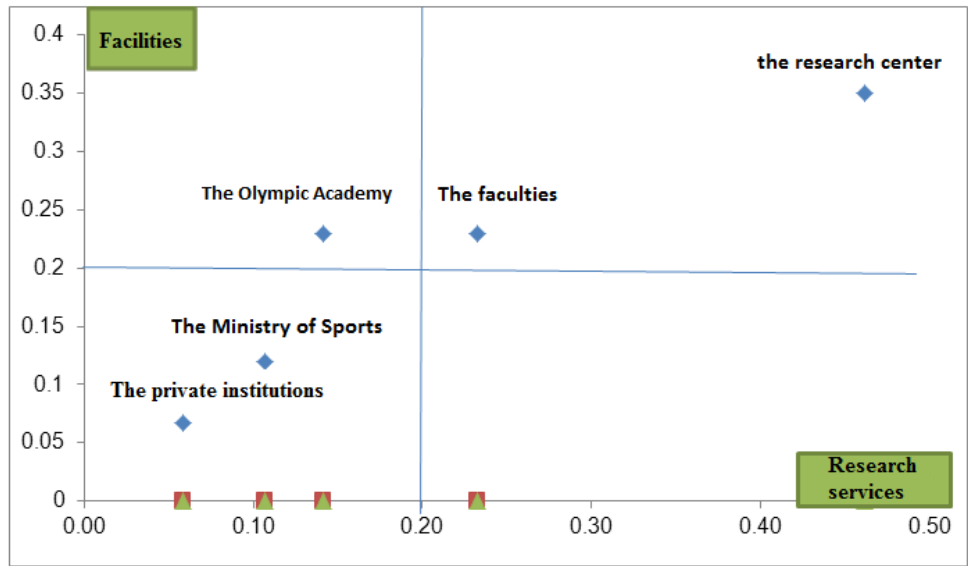

Figure 2. Perceptual map based on the variables of facilities and research services.

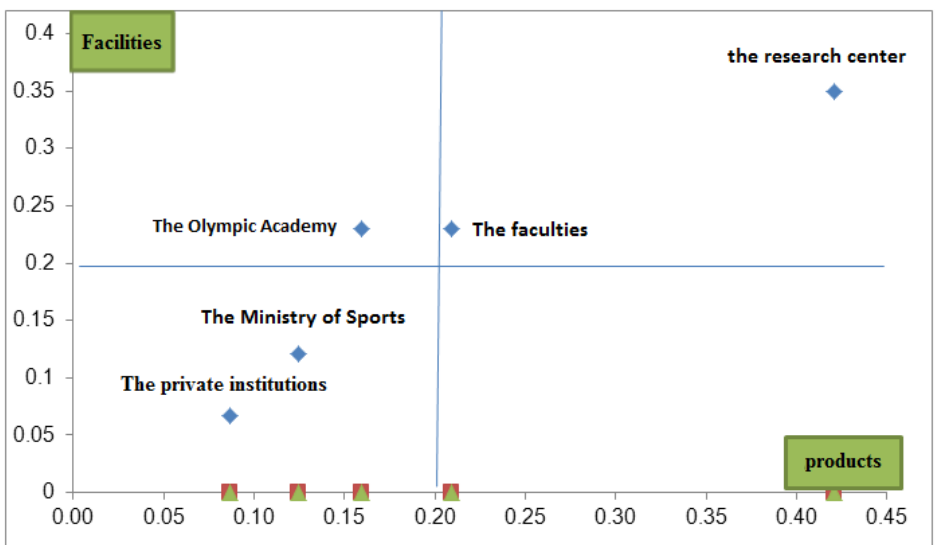

Figure 3. Perceptual map based on variables of facilities and products.

As shown in Figure 4, the Physical Education Research Center has a much better position than other competitors in the fields of educational services and research services, and in this area only the physical education faculties are close to the research Center.

As shown in Figure 5, the Physical Education Research Center has a much better position than other competitors in the fields of research products and services. In this area, only physical education faculties are close to the research Center. In this regard, the National Olympic Academy has a better position than the previous ones.
As shown in Figure 6, the Physical Education Research Center has a much better position than other competitors in the fields of products and educational services. In this area, only physical education faculties are close to the research Center. In this regard, the National Olympic Academy has a better position than the previous ones.

\section{DISCUSSION}

An organization will gain competitive advantage when it becomes highly valued by its customers compared to other competing organizations. According to Dolatabadi et al. (2011), there are two 
distinctly competitive types. The cost advantage and distinctive advantage, that is, customers observe the fundamental difference in product and organization characteristics compared to competitors. Therefore, the Physical Education Research Center should provide services and products that are unique and distinct in the society in order to create difference in competition, and consequently a competitive advantage. According to the research of Talebpour and Rasooli (2012), it is necessary to create a distinction compared to the competitors to create brand awareness and brand association. This could be achieved through using modern technology like online services (26).

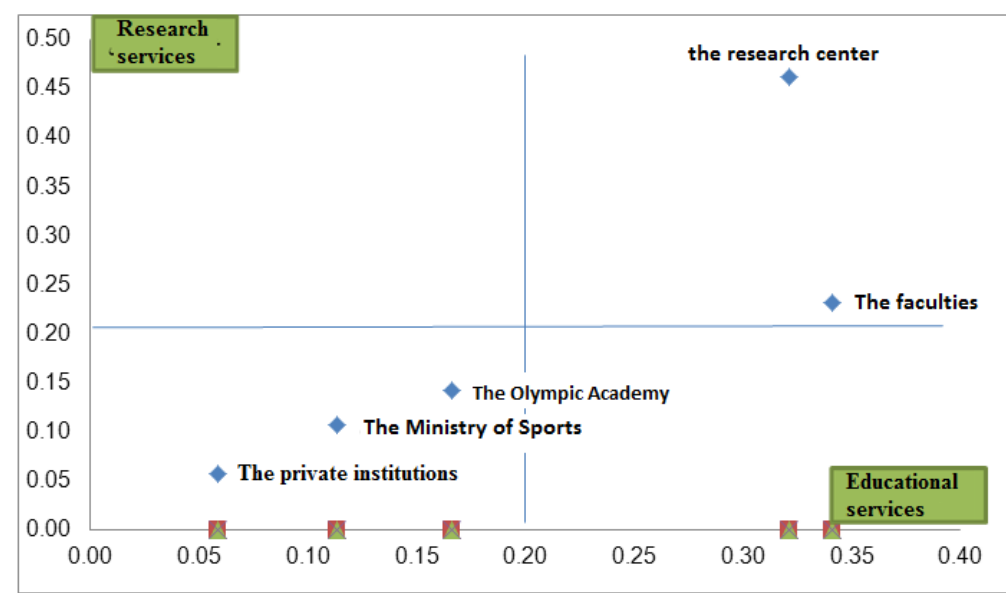

Figure 4. Perceptual map based on the variables of educational services and research services.

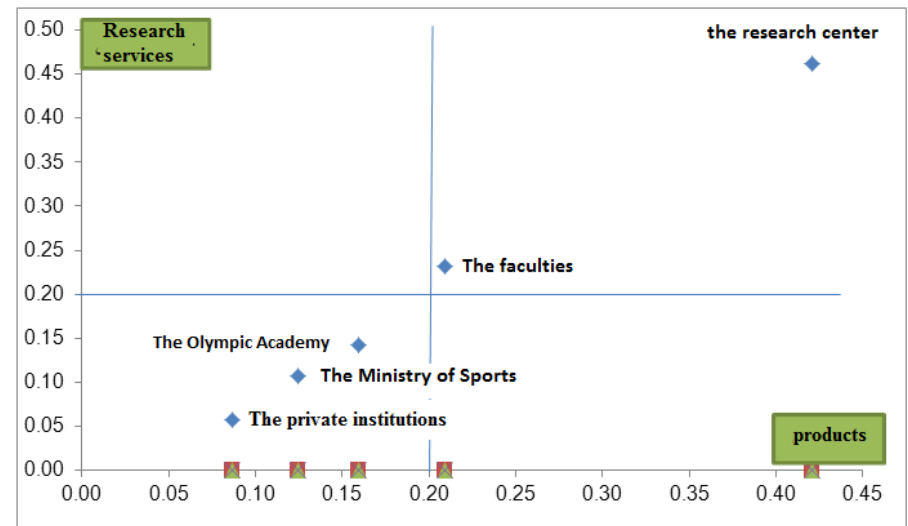

Figure 5. Perceptual map based on variables of research services and products.

Investigating the competitive characteristics of the Research Center showed that the activities and tasks of the research Center are known and ongoing in four areas including research services, educational services, facilities and products. Hierarchical analysis showed that prioritizing the importance of these domains from the perspective of the scientific community of the country's sport implies that, according to the name and mission of the research center, research services are initially far from other areas. After that, the educational services are followed by the facilities and, ultimately, the products of the research Center.

Certainly what is expected from the Physical Education Research Center includes research activities, which introduces the research Center as a center for knowledge management. Tess (1993) and Moharramzadeh and Akbari (2013) consider the exclusiveness and distinctness in providing services as effective on brand image. Therefore, as with the findings of Kalafatis et al. (2001), scientific index and relevant programs are more in the minds of the audiences of scientific 
organizations. According to Bagheri et al. (2010), University identity and culture is the most effective factor affecting brand image, which is true regarding the identity of the research Center.
Spreading the research findings is the most important part of research institutes that can be happened more influential through social networks (25).

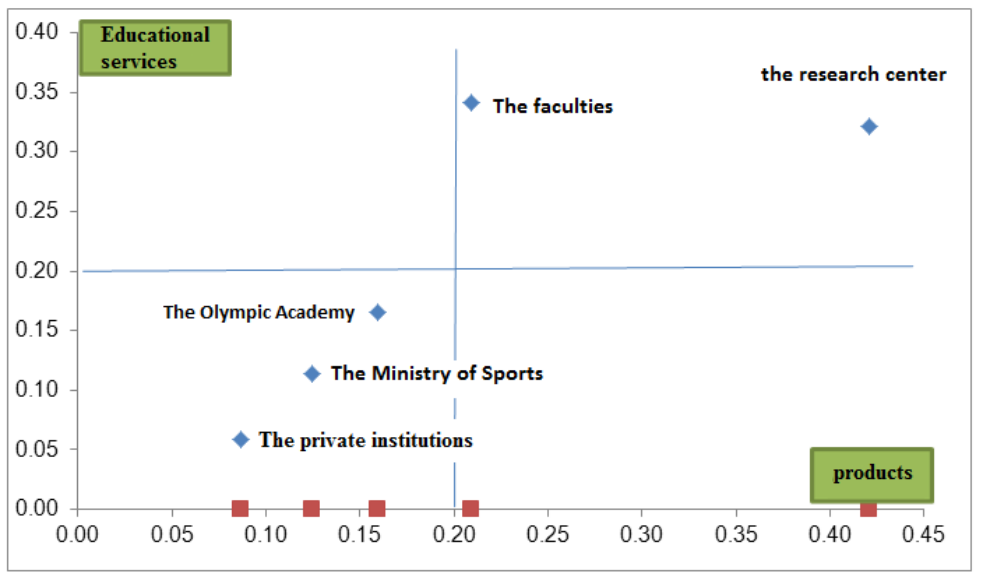

Figure 6. Perceptual map based on the variables of educational services and products.

In addition, the research activities of the research Center in the form of holding courses, workshops and finally, the Ph.D. course was retained more in the audience's mindset. In this regard, Kalafatis et al. (2001) and Megan et al. (2011) confirmed the effect of educational programs on scientific organizations. The Physical Education Research Center, in parallel with its research activities, offers nationwide educational programs that are effective in shaping the image and positioning the brand in the minds of the audience. In this regard, physical characteristics from Wilson (1999), Bagheri et al. (2010), and Hosseini et al. (2012), as factors that are apparently seen, were introduced as an important factor in brand image, which are consistent with the findings of this research. Rauschnabel, et al, (2016) emphasized that online courses and webinar software are few facilities that can make better market place.

Knowledge management processes can include knowledge creation, knowledge organization, knowledge transfer, knowledge application, and the creation of new knowledge (5). The research Center was also responsible for knowledge creation by carrying out research projects, support for scientific projects, dissertations and student dissertations. By creating scientific bases, organizing national and international conferences, workshops and scientific meetings, publishing books and scientific publications, organizing and transferring knowledge, and ultimately, through prototyping and manufacturing of products and scientific achievements, it makes them applicable. Of course, the Center of Physical Education, by strengthening its relationship with other bodies and the needs assessment of the country's sports community, can carry out customized and required research and thus ensure the application of its research. As stated, educational services such as holding workshops and meetings are also in the direction of knowledge transfer. The facilities of the research Center as a means of producing knowledge and products are also applications of the research, all of which are ultimately defined in line with research services of the research Center.

In the meantime, the competitors of the Physical Education Research Center were identified in the studied areas including the faculties of the physical education, the Study Center of the Ministry of Sports and the general offices for the Ministries of Sports and Youth, the National Olympic Academy and private institutions. In the field of specialized facilities, the Physical Education Center had the best position among its rivals. Having a well-equipped laboratory and a proper library, as mentioned in the previous section, has made the scientific 
department of the country to consider the research Center higher than other competitors. Kalafatis et al. (2001), Wilson (1999), Kennedy (1997), Bagheri et al. (2010) and Hosseini et al. (2012) also emphasized the importance of facilities, after which the National Olympic Academy advanced equipment, which allows for various sports tests. After the Olympic Academy, there are physical education faculties all over the country with each having their own lab and library facilities, and, finally, the Ministry of Sports and Private Institutions. Since the main task of the Ministry of Sports and Youth is not research and educational matters, it is desirable to leave research projects and its research and training activities to external expert groups, so that in addition to focusing on the core mission of the organization they can obtain better quality work and avoid carrying out parallel work and spending extra time and money. This was also mentioned by Talebpour and Rasooli (2013). Moreover, contrary to what is referred to in Article 44 of the Constitution, the privatization debate in Iran is in bad conditions and, in particular, in the field of sport, and in different areas, the state of private organizations is not suitable which can be seen further in other areas.

As far as educational services are concerned, physical education faculties have a better status and are ahead of the research Center. According to Hosseini et al. (2012), this matter is crucial. The physical education center can with regard to its organizational authority and centrality, improve the status of workshops and hold shortterm specialized courses required by the community, especially the definition of engaging and attracting courses and by identifying new topics in different trends in physical education to excel in this area. In this area, the Olympic Academy is in the next position by holding special courses for sports federations.

In the field of research, as expected, the Center for Physical Education is at the highest level, followed by the Physical Education faculties and the National Olympic Academy. The National Olympic Academy has been conducting various research projects in the past years, and it can be said that by changing the state of management and changing the attitude of new managers, this issue is currently stagnant.
In the last field of products and research achievements, the research Center has been ranked the highest, followed by physical education faculties. Given the fact that the equipment industry is very weak in the country, and focus on it requires much knowledge and finance, and there is no specific custodian in the country, the discussion of new sports equipment is very weak. Of course, in recent years, with the arrival of industrial universities in the field of sports with the establishment of sports engineering centers, this issue has been taken into consideration. The Center for Physical Education has succeeded in connecting with these faculties and using the facilities and laboratory available in this area.

In the following, comparing the competitors of the Physical Education Research Center after the competitive characteristics and based on the perceptual maps drawn, it is observed that according to the two dimensions of facilities and educational services, the research Center and physical education faculties are in a better position than other competitors, and then there is the Olympic Academy. In two dimensions of facilities and research services, the Physical Education Centers are in a far better position than other competitors, and then there are faculties. This is true for both the facilities and products. In the areas of educational and research services, the Research Center and Physical Education faculties are in a better position, and the National Academy of Olympics contrary to the previous areas is in a bad situation. In the areas of research services and products, although the physical education faculties rank second behind the research Center, their status is still not ideal. Finally, in relation to products and facilities, the research Center and physical education faculties have a better position than other competitors. In all of these maps, it can be observed that private institutions are in the worst competitive state, which is not desirable for the development of sports and physical education in the country. The Ministry of Sports Studies Center, although having a high level of funding and high costs for parallel and inefficient research projects, is not in a desirable situation, and as it was said, given that it has other core tasks, the Ministry is better to leave its research and education affairs to specialized organizations. 
Based on the results, it should be mentioned that educational and research organizations such as the Center for Physical Education should introduce their organization as an effective unit in the field by establishing communication units with industry and adopting appropriate strategies. This issue should be strengthened by the Public Relations Unit of these organizations in order to inform the Center's effective activities to the executive and educational services sectors. According to the technology progress and the great impact of digital environment on education and research area, SSRI should start utilizing online education systems, webinar and online congress software to get a better place among its competitors. Paying more attention to social networks and using them to expend research findings and should be SSRI priority for creating more brand awareness. Designing promoting programs and campaigns with collaboration of national and international well-known researchers and athletes will also help for making desirable brand personality as Rutter, et al (2017) mentioned.

\section{CONCLUSION}

Ultimately, the goal is to achieve brand loyalty after attracting customers to the products and services of the research Center. Brand loyalty is the ultimate goal of any company that has a brandspecific product. Priority or preference to buy a special brand in a series of products by the customer is brand loyalty. If customers find out that their brand is a design and combination of a product of high quality and is offered at an affordable price, this perception becomes a basis for repeating the subsequent purchases and is even highly effective in recommending the product to others. In a challenging and turbulent environment today, the role of brand as a consumer decision making guide becomes more and more highlighted day by day. Branding should therefore be considered as a continuous activity in all modes.

\section{APPLICABLE REMARKS}

- SSRI is in the desirable position right know.

- SSRI and other organizations should identify their opponents and their position among them frequently.

- Perceptual mas helps managers for brand positioning.

\section{REFERENCES}

1. Cutler PH, Keller LK. Marketing management. 12th ed. Prentice Hall College Div; 2005.

2. Mahmoudi L, DavoudiA, Sadeghi T, Kafashpour A, Yousefzadeh, F. Strategic positioning of the brand of SADERAT Bank from the point of view of legal customers, production units of South Khorasan. Marketing Management Magazine. 2002; 19 (2): 67-91.

3. Darling JR. Successful competitive positioning: the key for entry into the European consumer market. European business review. 2007; 2: 200-210.

4. Chen JS, Uysal M. Market positioning analysis: A hybrid approach. Journal of tourism research. 2008; 15: 195 210.

5. Rasooli M. The positioning of the brand of the Physical Education Research Center and providing promotional solutions. Research Center for Physical Education and Sport Sciences. Tehran. 2013.

6. Asikhia O. Positioning a bank service in Nigeria: a conceptual framework, International journal of business and management. 2010; 5 (8): 146-153.

7. Benedict JE, Hans AC, Steen V, Tripp B, Ten JM. Perceptual mapping based on idiosyncratic sets of attribute. Journal of marketing research. 1999; 15: 38-56.

8. Ries A, Trout J. The battle for your mind. 20th ed. New York: McGraw-Hill. 2001.

9. Rasooli M, Talebpour M, Javadipour M, Ghodsi P, Sa'atchian V. The model of industry and university association in the field of sport. The first international conference on privatization and investment in sport. Tehran. 2012.

10. Alizadeh MH, Elahi A. Strategic Planning for the Development of Sport Sciences Research of the Islamic Republic of Iran. Research project of the Center of Physical Education and Sport Sciences, Ministry of Science, Research and Technology, Tehran. 2008.

11. Gotsi M, Wilson A. Corporate reputation management: "living the brand", Management Decision. 2001; 39 (2): 99-104. 
12. Kalafatis SP. Positioning strategist in business market. Journal of Business and industrial marketing. 2001; 4: 416437.

13. Price L, Matzdorf F, Suckley L, Aghahi H. The impact of facilities on student choice of university. Facilities journal. 2003; $21(10) ; 212-222$.

14. Ivy J. Higher education institution image. International Journal of educational management. 2008; 15: $275-282$.

15. Dourate P, Alves H, Raposo M. University image: a structural equation model approach. International review on public and non-profit marketing. 2010; 7: 21-36.

16. Arpan L, Raney A, Zivnuska S. A congnitive approach to understanding university image. Corporate communication; an international Journal. 2003; 8: 115-132.

17. Palacio A, Menses G, Perez P. The configuration of the university image and its relationship with the satisfaction of the student. Journal of educational administration. 2002; 40: 486-505.

18. Martinez E, Buil I, Chernatory LD. Brand Extension Effects on Brand Equity: A Cross-National Study Journal. 2009; 18 (2): 71-88.

19. Cowart KO. Fat so? Managing the Effect of Obesity Stereotypes on Customer Evaluations of Service Organizations. Electronic Theses, Treatises and Dissertations. The Graduate School. Florida State University Libraries. 2010.

20. Gorchels L, Gordon L. Building a university brand from within: university administrator's perspectives of internal branding. Services marketing Quarterly. 2009; 5: 54-68.

21. Bagheri M, Erfanifar E. Designing an Effective componential Model on Organizational Image of Imam Sadiq University (as). Strategic Management Thought. 2010; 4 (2): 43-77.

22. Hosseini M, Farhadi Nahad R. Identification of brand image measurement scales at university. Quarterly Journal of Educational Measurement .2012; 8: 109-132.

23. Dastoom S, Ramezannezhad R, Benar N, Rasooli R. Survey of interactions administrative departments and industry sport in Iran Based on the Analysis Documents and structural. Applied Research of Sport Management. 2013; 2(2): 91-108.

24. Saatchian V, Hadavi F, Akbari Yazdi H, Saffari, M. Strategies and the Consequences of Relation Management between Physical Education and Sport Science College and Executive Part of Sport Industry. Strategic studies on youth and sports. 2015; 14 (27): 193-208.

25. Careaga A. The elements of brand-building in higher education: The role of strategy, research and internal engagement. : Journal of Education Advancement \& Marketing. 2017; 2 (3): 280-294.

26. Rauschnabel PA. Brand management in higher education: The University Brand Personality Scale, Journal of Business Research. 2016. http://dx.doi.org/10.1016/j.jbusres.2016.01.023.

27. Rutter R, Lettice F, Nadeau J. Brand Personality in Higher Education: Anthropomorphized University Marketing Communications. Journal of Marketing for Higher Education. 2017; 27 (1); 19-39. 